\title{
DEVELOPING GUIDELINES FOR THE DISTRIBUTION OF SCARCE MEDICAL RESOURCES DURING THE COVID-19 PANDEMIC. THE ESTONIAN CASE
}

\author{
Margit Sutrop ${ }^{1,2}$ and Kadri Simm ${ }^{1}$ \\ ${ }^{1}$ University of Tartu and ${ }^{2}$ University of Helsinki
}

\begin{abstract}
This article provides an introduction to Estonian clinical ethics recommendations concerning the distribution of limited health care resources during the COVID-19 pandemic. We will give a short overview of the process of compiling the Estonian document, including stakeholder involvement, engagements with comparable international documents, main internal debates and lessons learned for the future.
\end{abstract}

Keywords: Estonia, COVID-19, coronavirus, pandemic, recommendations for hospitals, clinical ethics, distribution of resources, triage, disaster medicine, ethical principles, dilemma

DOI: https//doi.org/10.3176/tr.2020.2.08

\section{Introduction}

March 2020 witnessed an unprecedented level of global bioethics activity, both in professional as well as in mainstream media and networks. Amongst the most challenging of these debates during the COVID-19 pandemic were attempts to formulate clinical ethics guidelines on how limited medical resources and services ought to be allocated should the needs exceed availability. By mid-April most European countries had at least some form of ethical guidance in place regarding these difficult decisions.

Was such a flurry of activity necessary? Few have doubted the importance of such debates in mainstream media, blogs and online deliberations, because they contributed to informing the public about the stark choices involved in triage. In some countries the debates may even have indirectly influenced a more rapid adoption of emergency measures in order to avoid the necessity to make such choices in the first place. Some have questioned whether medical professionals actually needed such guidance, due 
to the fact that emergency and disaster physicians have regular experience with critical situations, and the existing clinical guidelines might be extended to cover the new pandemic (McCullough 2020). Indeed, it is the case that there has been a proliferation of guidance documents on international, national, professional and local levels, resulting in potential inconsistencies, plenty of duplication and general information overload targeted at clinical decision-makers (Huxtable 2020).

However, not all countries had previously formulated written clinical guidelines for the allocation of intensive care treatments that could also have been used in exceptional, resource-limited circumstances. For example, the Estonian Society of Anaesthesiologists recognised during the Covid-19 pandemic the need to formulate exact triage rules for intensive care units. According to the oral communication the anaesthesiologists appreciated the work on the recommendations and welcomed additional support in thinking through the ethical basis of difficult decisions in emergency situations. In the following we will describe the process of compiling recommendations for Estonian hospitals regarding the distribution of limited health care resources during the Covid-19 pandemic, including stakeholder involvement, engagements with comparable international documents, major internal debates and lessons learned for the future.

\section{Timeline and stakeholders}

The Estonian Government declared an emergency situation on 12 March 2020 in order to respond to the spread of the coronavirus in Estonia. At first, the situation was meant to last until 1 May 2020, but on 24 April the emergency situation was extended until 17 May because of ongoing spread of the virus.

The initiative for drafting the recommendations for Estonian hospitals for distribution of limited health care resources during the Covid-19 pandemic came from the Crisis Management Committee at the North Estonia Medical Centre (NEMC). The Republic of Estonia's Health Board had on 24 March made the two largest hospitals, NEMC in Tallinn and Tartu University Hospital (TUH) responsible for the management of Covid-19 treatment in all hospitals in either the northern or the southern regions of Estonia. The Crisis Management Committee at NEMC asked the hospital's ethics council to work out guidelines for the allocation of health care resources in the Covid-19 pandemic. The Ethics Council of NEMC met on 25 March and discussed the then already available Italian guidelines (Vergano et al 2020) and some scholarly articles (Rosenbaum 2020 and Ezekiel et al 2020) addressing the fair allocation of medical resources in a situation of high demand for intensive care beds and respirators. That day the first patient with Covid-19 diagnosis had died and 404 cases had been diagnosed; 28 people were hospitalized and 7 needed intensive care. The worst-case scenario forecast the overwhelming of ICUs across the country within 2-3 weeks. The ad hoc Covid-19 Scientific Council was formed to advise the Estonian Government, and on 24 March the council predicted that in two weeks more than 100 patients, after three weeks even a total of 200-300 patients might 
need intensive care. The estimated maximum national capacity of ventilated ICU beds was 130 ( +75 more ventilators available, but lacking adequately trained staff). At the moment, occupancy of the 3rd level intensive care beds in Estonia was $49 \%$.

After the discussion of the first draft at the extraordinary meeting (25 March) of the Ethics Council of NEMC, the decision was made that instead of a regional document pertaining only to hospitals belonging to the northern region of Estonia, coordinated by NEMC, it would be better to address recommendations for all Estonian hospitals; therefore, an invitation was sent to Tartu University Hospital, which is responsible for all hospitals in the southern part of Estonia, with the goal of preparing a joint document. After the heads of the two hospitals' crisis committees, Professor Peep Talving (Medical Director of NEMC) and Professor Joel Starkopf (Head of the Clinic of Anaesthesiology and Intensive Care at UTH), had agreed that we should prepare a joint document, the Clinical Ethics Committee at Tartu University Hospital became a second partner in this process. The third partner who helped draft this document was the interdisciplinary Centre for Ethics at the University of Tartu who, in cooperation with some external experts in medicine, ethics and law volunteered to study other available international documents and prepare an ethical and legal analysis of the recommendations. The initial draft of the document was written during the last week of March by members of the two hospital ethics committees and the Centre for Ethics, and then submitted for consultation to experts in medicine, bioethics and law, and edited accordingly. The draft was then worked on and shared via Google docs, with hours-long Skype audio sessions facilitating the joint formulation. The responsibility for the analysis in clinical medicine was assumed by Dr Jaan Tepp and Dr Kristo Erikson from NEMC. The legal analysis was prepared by Professor Jaan Ginter (UT) and the ethical analysis by Professor Margit Sutrop (UT) and Associate Professor Kadri Simm (UT). The process was coordinated by Andra Migur from NEMC.

Estonia is a small country (population 1.3 million), and most of its medical practitioners have been trained in one medical school, at the University of Tartu. Thus, there were numerous existing personal contacts and overlapping institutional affiliations between the members of the three partner institutions that facilitated the cooperation. The ethics committees of both medical centres (the two largest in Estonia) are interdisciplinary and, in addition to physicians, they also include representatives from nursing, midwifery, philosophy/ethics, counselling, and patient advocacy.

The final version of the Recommendations was coordinated with the Health Board and the President of Estonia. A press release announcing the availability of the guidelines on the NEMC homepage and their distribution to all Estonian hospitals was published on 6 April 2020 and an article in the major daily newspaper "Postimees" explained the ethical approach (Sutrop 2020). The press release stressed that these instructions should be taken as preventive measures, which hopefully would not be necessary, but which, should the situation deteriorate, would ensure that doctors know on what to base their decisions.

The media response was quite lively (around 20 items of media coverage); the 
recommendations were mentioned by all daily newspapers and various radio and TV channels. On 13 April, the Committee of Social Affairs of the Estonian Parliament discussed the recommendations at their online meeting. Dr Kristo Erikson (NEMC) and Professor Margit Sutrop (UT) explained the process of drafting the recommendations and answered questions from MPs and representatives of the Estonian Ministry of Social Affairs. Although the joint initiative of two major hospitals' ethics committees and the Centre for Ethics was appreciated and viewed as a good example of cooperation, there was some criticism from the representatives of the ministry that they had not been involved in the process. Also, there were questions about the timing of the recommendations, since by the time the document was published, it had already become clear that the lockdown measures enforced by the government to control the virus had been effective, and that the number of patients needing hospital treatment, especially intensive care, was much lower than expected (on 6 April Estonia had 1108 confirmed diagnosed cases, 129 were hospitalized, including 14 in intensive care). It is important to stress that already during the guideline compilation process Estonian intensive care units were not overwhelmed; in fact, these critical prognoses never materialised. The highest number of ventilated patients was 20 (on 3 April), and the highest number of hospitalisations was 157 (on 12 April).

Thankfully, the pandemic in Estonia has so far not overwhelmed the health care system and the emergency situation ended on Sunday at midnight (17 May) when there were still 44 people hospitalised, 4 in intensive care and Estonia overall had had 64 Covid-19-related deaths. Estonia's southern neighbour, Latvia, was even less affected (19 deaths as of 18 May) while in Finland, Estonia's northern neighbour, the infection rates and casualties were slightly higher (Häyry 2020). Estonia has not had excess death rate due to Covid-19 in March-April 2020.

\section{A moral compass for doctors in making difficult decisions}

During these few intensive weeks of global bioethical deliberation, synchronised work on various national and professional guidelines was accomplished through the sharing, debating, as well as criticizing of numerous documents. For the Estonian guidelines, in addition to the Italian guidelines (Vergano et al 2020), the Austrian (Österreichische.... 2020), Belgian (Meyfroidt et al 2020), German (Deutsche.... 2020), and Swiss Academy (Swiss... 2020) guidelines were studied carefully. We also looked at the UK NICE Covid-9 rapid guideline (NICE 2020) and a guidance note of the British Medical Association (BMA 2020), as well as the Hastings Centre Guidelines for Institutional Ethics Services Responding to Covid-19 (Berlinger et al 2020). Ethical frameworks varied, although a broadly utilitarian approach well established in the field of disaster bioethics was frequently employed. In a crisis situation, the focus shifts from the patient-centred approach of regular medicine to a community-based approach which foregrounds collective values such as solidarity, reciprocity and safety (Sutrop 2011a, Sutrop 2011b). An alternative perspective was 
argued for in the Opinion issued by the German Ethics Council (Deutscher Ethikrat 2020), which prioritized the rights-based account and thereby differed considerably from other comparable documents where the more communitarian and common good-based rationale was justified. The Opinion issued by the German Ethics Council (2020) has been praised for arguing against the utilitarian principle, according to which the aim is to save maximum life-years, whereas according to the rights-based ethics it is important to avoid any discrimination and respect everybody's right to treatment (Lübbe 2020). However, this approach has also been criticised as counterintuitive (one cannot decide to give equal weight to a patient who has minutes to live and a patient who could live for 50 more years!) or as leaving clinical decisionmakers without guidance on how to act when there are two conflicting obligations. This was the case with ethical dilemmas faced by doctors in China, Italy, and Spain, where doctors were put in a situation where there were insufficient intensive care beds for all who needed them, and the doctors had to decide which duty was stronger: the duty to help or the duty not to harm.

By taking the respirator from the patient who arrived earlier but had the worse prognosis and giving it to the patient with a better medical prognosis (the one who would most likely need the respirator for fewer days, therefore making it possible to help more patients), one would possibly save more lives but violate the duty not to harm. No matter which option the doctor chose, $\mathrm{s} /$ he failed to carry out an action that $\mathrm{s} / \mathrm{he}$ had reasons to do. Notice that even if $\mathrm{s} / \mathrm{he}$ was not able to decide, not handling the dilemma is also a choice, which leads to the same result as prioritising the first option - to help the patient who happened to arrive earlier. Whatever the doctor had done, it would probably result in regret, even when s/he understood rationally that $\mathrm{s} /$ he did the right thing.

Such choices require a capacity for moral deliberation, for weighing different values, for prioritizing certain important ethical principles over others and, ultimately, for making an ethically justified choice. These are complex skills, but they can be trained (Simm 2020). In Estonia the Centre for Ethics has trained hundreds of medical professionals over the past ten years with the help of the Value Game for Medics (Values Game for Medics n.d.), which focuses specifically on developing ethical deliberation skills in cases of moral dilemmas. During the time of the writing of the recommendation to hospitals, the members of the ethics committees realized that the hospital will be confronted with ethical dilemmas similar to the ones they remembered from the training with the Values Game for Medics, and therefore they felt better prepared to formulate guidance for dealing with the ethical dilemmas in exceptional, resource-limited circumstances.

However, as later discussions in the hospitals showed, many Estonian physicians believed that it would have been very difficult for them to act according to the guidelines, because physicians are trained to act according to the Hippocratic oath, which states that the doctor has to provide life-saving treatment. Thus, if in the resource-limited circumstances, a physician is put under pressure to stop active treatment of a patient because the resources would be more effectively used for some other patient, the physician may perceive this situation as unethical and in 
contradiction to the values and principles of the Hippocratic oath. In addition, they also perceived a risk of penalty, because, according to criminal law, withholding help was punishable. In anticipation of such situations, as soon as the recommendations were made public, one attorney specializing on medical law announced publicly that he was prepared personally and free of charge to defend in court the medical professionals who follow the guidelines (Nõmper 2020).

\section{What is specific about the Estonian recommendations?}

The Estonian instructions emphasise that the four well-known principles of medical ethics - justice, beneficence, nonmaleficence and autonomy - continue to be valid in the crisis situation, but the relations between them are different. In a normal situation, clinical medicine is patient-centred: the duty of the medical staff is to take care of each patient's wellbeing and health (the principle of beneficence), avoid causing harm (the principle of nonmaleficence), consider the patients' individual preferences and values (honouring of autonomy and human dignity) and treat all patients equally while avoiding discriminating anyone because of their age, gender, mental or physical disability (the principle of justice).

The Estonian instructions stressed that age is not a direct criterion for making decisions about intensive care. The main criteria for starting or continuing of intensive care should be the medical outlook of successful treatment and a favourable prognosis for the quality of future life. The patients' actual clinical status, their general health status, accompanying diseases and the patients' will are also considered. Although accompanying and chronic diseases are known to be the main factor influencing the success of treatment, and more advanced age is statistically more frequently associated with accompanying and chronic diseases, neither in an ordinary situation nor during the COVID-19 pandemic should patients be discriminated against on an age basis.

The Estonian instructions state that only medical criteria and the patients' will, i.e. whether they want to receive intensive care at all, should be considered when administering or continuing treatment. In Estonia, prior considerations of the patients' will resulting from the principle of autonomy have often not received sufficient attention when intensive care decisions are made. We thus recommended that to prevent a situation where others must guess what the patient really wanted, the patient should be asked in advance what should be done if the situation turns critical. The Estonian instructions also pay great attention to caring and human dignity. They stress that, if active treatment is interrupted, everything possible must be done to relieve patients' sufferings and to ensure their humane and caring treatment.

The guidelines reminded doctors and hospitals that, because of the ban on visiting due to the quarantine, patients may feel abandoned and lonely. We recommended that hospitals should offer new options, including information and communication technology devices, so that patients could keep contact with their families. Also, we suggested that hospitals should recruit more psychologists, pastoral counsellors and/ 
or clergy who would take care of the patients' and medical staff's mental wellbeing and stressed the importance of supportive and empathic communication with patients' family members. Finally, the Estonian instructions also emphasised the significance of generous cooperation between different hospitals and their staff. The last principle of the instructions stressed that health care providers and hospitals all over Estonia support one another in the difficult situation and cooperate by sharing their expertise, skills, and resources.

\section{Lessons learned}

The Covid-19 epidemic arrived at different times in different European countries. Estonia was luckily among those countries which could learn from the painful experience of other countries. Because the effect of protective measures was so thorough, in Estonia the situation in spring 2020 did not worsen as much as it was predicted and feared. Therefore, questions began to be raised as to whether drafting such drastic recommendations for the allocation of medical resources in Covid-19 pandemic made sense at all.

It is our view that the formulation of such guidelines was important at the time (including the effect of disciplining people to adhere to the restrictions), for at the time of drafting the recommendations no one could really know whether they would be needed. We do not even know for sure now, in May 2020, for there has been talk of a possible second wave of the epidemic in autumn 2020. The extra time given to us due to the earlier start of the pandemic in southern Europe allowed sufficient preventive quarantine measures to function efficiently, and although schools, universities, theatres, cinemas, gyms and shopping centres were closed, the lockdown was never of a severity comparable to Italy, France, Spain, UK. Stricter measures were applied on the largest Estonian island, Saaremaa that had an early high infection rate. Thus, in some sense this has been a 'good crisis' that has allowed for thorough preparation on all levels, including the ethical aspects of scarce resource allocation. But the debates during the drafting of the guidelines as well as in the mainstream media also highlighted numerous fundamental ethical challenges that need addressing within the wider health care system, crisis or not.

Estonian medical professionals did not need to start applying the strict resource allocation rules in practice. We therefore do not know if, how, and with what practical, psychological, social and legal implications the more utilitarian disaster thinking would have replaced the traditional deontological medical frameworks.

COVID-19 especially threatened the lives and well-being of those who were already vulnerable due to comorbidities, and the latter is often correlated with age. As is well known, the virus has taken disproportionate toll on the elderly (in Italy over $83 \%$ of the casualties have been aged 70 or over, Statista... 2020). The use of invasive and intense ICU measures in these instances raised concerns about their clinical reasonableness and the futility of the treatment: a life might be formally saved, but the quality of that life and the costs of maintaining it might be 
unacceptable. Furthermore, many of these difficult clinical decisions are bound up with the availability and quality of palliative care.

These concerns link closely with the broader topic of patient wills. In Estonia there is no tradition of specifying a personal account of acceptable medical interventions and treatments in a living will. Indeed, often these topics are not discussed amongst family members, let alone with one's physicians or other healthcare workers. At a time of crisis the implementation of patient preferences in terms of medical interventions might not always be possible, but it may still contribute to overall decision-making, perhaps removing some difficult dilemmas (see McCullough 2020 for a more radical view that patients' wishes should play absolutely no role in disaster resource allocations). One of the 'lessons' of the pandemic, therefore, is that we need collectively as a society to address the topic of living wills during 'normal times'.

We also considered that it is a weakness of the Estonian healthcare system that palliative care possibilities are not available for everyone who needs them. Thus, we were aware that even if the guidelines stress that should active treatment be interrupted, everything possible must be done to relieve patients' sufferings and to ensure their humane and caring treatment, this may not always be possible, as the resources are not always there.

Last but not least - the crisis highlighted the importance of good communication rules and best practices when medical professionals interacted with patients and their families. We also witnessed at least one case where our recommendation that hospitals should offer new options, including information and communication technology devices, so that patients could keep contact with their families was followed: 30 patients in one hospital received iPads to communicate with their families.

Judging from the reactions of journalists and politicians to the publication of the guidelines, one can see how the manifestation of such a situation and the need for such harsh decisions would have been a shock to the public. When we who were responsible for the ethical analysis of the guidelines were in the discussion at the Estonian parliament, and we were asked how it happened that they were made public, we answered that hospital ethics committees never planned to keep them secret, for secrecy is what makes people anxious. However, in a crisis situation trust in the medical system and doctors is crucial.

We also believe that thinking through and publicly discussing ethical choices in a crisis situation furthered cooperation between physicians and ethicists and also explained to the public what the choices behind the decision were. Likewise, drawing up such a document heightened awareness of the need to agree on the ethical foundations of medical regulations, brought out weaknesses in the Estonian medical system, and clarified the topics that should continue to be worked on once the crisis had passed. 


\section{Acknowledgements}

We acknowledge the support of the Centre of Excellence in Estonian Studies (European Union, European Regional Development Fund). Margit Sutrop is also grateful to the Kone Foundation which enabled her to do research at the Helsinki Collegium for Advanced Studies at the University of Helsinki.

We are very thankful to Tiina Kirss and Ilmar Anvelt for their help with English expression, to Mari-Liisa Parder for her careful editing and to Õnne Allaje and Laura Lilles-Heinsar for their help with references.

Addresses:

Margit Sutrop

Centre of Ethics

University of Tartu

Jakobi 2

50090 Tartu, Estonia

E-mail: Margit.Sutrop@ut.ee

Tel.: +372 5207183

Kadri Simm

Department of Philosophy

University of Tartu

Jakobi 2

50090 Tartu, Estonia

E-mail: Kadri.Simm@ut.ee

Tel.: +372 5129219

\section{Internet sources}

Berlinger, N., Wynia, M., Powell, M., Hester, M., Milliken, A., Fabi, R., Cohn, F., Guidry-Grimes, L. Watson, J. C., Bruce, L., Chuang, E. J., Oei, G., Abbott, J., and N. P. Jenks (2020) "Ethical framework for health care institutions responding to Novel Coronavirus for institutional ethics services responding to COVID-19. managing uncertainty, safeguarding communities, guiding practice". The Hastings Centre, 16 March. Available online at $<$ https://www.thehastingscenter. org/ethicalframeworkcovid19/>. Accessed on 19 May 2020.

BMA (2020) "COVID-19: ethical issues. a guidance note". Updated 12 May. Available online at $<$ https://www.bma.org.uk/advice-and-support/covid-19/ethics/covid-19-ethical-issues>. Accessed on 19 May 2020.

Deutsche Interdisziplinäre Vereinigung für Intensiv- und Notfallmedizin (DIVI) (2020), Entscheidungen über die Zuteilung von Ressourcen in der Notfall- und der Intensivmedizin im Kontext der COVID-19-Pandemie. Klinisch ethische Empfehlungen der Deutscnen Interdisziplinären Vereinigung für Intensiv- und Notfallmedizin (DIVI), der Deutschen Gesellschaft für Interdisziplinäre Notfall- und Akutmedizing (DGINA), der Deutschen Gesellschaft für Anästhesiologie und Intensivmedizin (DGAI), der Deutsche Gesellschaft für Internistische Intensivmedizin und Notfallmedizin (DGIIN), der Deutsche Gesellschaft für Pneumologie und 
Beatmungsmedizin (DGP), der Deutschen Gesellschaft für Palliativmedizin (DGP) und der Akademie für Ethik in der Medizin (AEM)". 25 March. Available online at $<$ https://www.divi. de/empfehlungen/publikationen/covid-19/1540-covid-19-ethik-empfehlung-v2/file>. Accessed on 19 May 2020.

Deutscher Ethikrat (2020) "Solidarity and the responsibility during the Coronavirus crisis: ad hoc recommendation”. 27 March. Available online at <https:/www.ethikrat.org/fileadmin/ Publikationen/Ad-hoc-Empfehlungen/englisch/recommendation-coronavirus-crisis.pdf $>$. Accessed on 19 May 2020.

Lübbe, W. (2020) “Corona-Triage”. 15 March. Available online at $<$ https://verfassungsblog.de/coronatriage/>. Accessed on 19 May 2020.

Meyfroidt, G., E. Vlieghe, P. Biston, K. De Decker, X., Wittebole, P. Depuydt, Nam, N. G., Hermans, G., Joren, P., Ledoux, D., Taccone, F., and I. Devisch (2020) "Ethical principles concerning proportionality of critical care during the 2020 COVID-19 pandemic in Belgium: advice by the Belgian Society of Intensive Care Medicine". 18 March 2020. Available online at $<$ https://www. hartcentrumhasselt.be/professioneel/nieuws-professioneel/ethical-principles-concerningproportionality-of-critical-care-during-the-covid-19-pandemic-advice-by-the-belgian-societyof-ic-medicine>. Accessed on 19 May 2020.

NICE. National Institute for Health and Care Excellence (2020) "COVID-19 rapid guideline: critical care in adults". 20 March. Available online at <https://www.nice.org.uk/guidance/ng159/ resources/covid19-rapid-guideline-critical-care-in-adults-pdf-66141848681413>. Accessed on 19 May 2020.

Nõmper. A. (2020) "Kriisi süngeim tund arsti jaoks: valik patsientide vahel”. [The darkest hour of the crisis for the doctor: the choice between patients.] Available online at $<$ https://www.delfi.ee/news/ paevauudised/eesti/kriisi-sungeim-tund-arsti-jaoks-valik-patsientide-vahel?id=89478639>. Accessed on 19 May 2020.

Österreichische Gesellschaft für Anesthesiologie, Reanimation und Intensivmedizin (2020) “Allokation intensivmedizinischer Ressourcen aus Anlass der Covid-19-Pandemie. Klinisch-ethische Empfehlungen für Beginn, Durchführung und Beendigung von Intensivtherapie bei Covid19-Patientinnen". 17 March. Available online at $<$ https://www.oegari.at/web_files/cms_daten/ covid-19_ressourcenallokation_gari-statement_v1.7_final_2020-03-17.pdf>. Accessed on 19 May 2020.

Statista Research Department (2020) "Coronavirus (COVID-19) death rate in Italy as of May 13, 2020, by age group". Available online at $<$ https://www.statista.com/statistics/1106372/coronavirusdeath-rate-by-age-group-italy/>. Accessed on 19 May 2020.

Sutrop, M. (2020) “Margit Sutrop: Soovitused rasketeks valikuteks”. [Margit Sutrop: Recommendations for difficult choices.] Available online at <https://leht.postimees.ee/6944396/margit-sutropsoovitused-rasketeks-valikuteks $>$. Accessed on 19 May 2020.

Swiss Academy of Medical Sciences (2020) "COVID-19 pandemic: triage for intensive-care treatment under resource scarcity”. Updated 24 March. Available online at $<$ https://smw.ch/article/doi/ smw.2020.20229>. Accessed on 19 May 2020.

Values Game for Medics (n.d.) Available online at <https://www.eetika.ee/en/values-development/ values-game-medics $>$. Accessed on 19 May 2020.

Vergano, M., G. Bertolini, A. Giannini, G. Mistraletti, and F. Petrini (2020) "Clinical ethics recommendations for the allocation of intensive care treatments in exceptional, resource-limited 
circumstances". Available online at <http:/www.siaarti.it/SiteAssets/News/COVID19\%20 -\%20documenti\%20SIAARTI/SIAARTI\%20-\%20Covid-19\%20-\%20Clinical\%20Ethics\%20 Reccomendations.pdf $>$. Accessed on 19 May 2020.

\section{References}

Huxtable, R. (2020) "COVID-19: where is the national ethical guidance?”. BMC Med Ethics 21, 32. https://doi.org/10.1186/s12910-020-00478-2

McCullough, Laurence B. (2020) "In response to COVID-19 pandemic physicians already know what to do". The American Journal of Bioethics, 23 April. doi: 10.1080/15265161.2020.1754100

Ezekiel, E., Emanuel, M. D., Persad, G., Upshur, R., Thome, B., Parker, M., Glickman, A., Zhang, C., Boyle, C., Smith, M., and J. P. Philips (2020) "Fair allocation of scarce medical resources in the time of Covid-19". The New England Journal of Medicine. Available online at $<\mathrm{https}$ ://www. nejm.org/doi/full/10.1056/NEJMsb2005114. Accessed on 19 May 2020.

Häyry, M. (2020) “The COVID-19 pandemic: a month of bioethics in Finland”. Cambridge Quarterly of Healthcare Ethics, 20 April.

Rosenbaum, L. (2020) "Facing Covid-19 in Italy - ethics, logistics, and therapeutics on the epidemic's front line". The New England Journal of Medicine, 18 March. Available online at $<\mathrm{https}$ ://www. nejm.org/doi/pdf/10.1056/NEJMp2005492?articleTools=true>. Accessed on 19 May 2020.

Simm, K. (2020) "Ethical decision-making in humanitarian medicine: how best to prepare?". Disaster medicine and public health preparedness, 10. 1017/dmp.2020.85

Sutrop, M. (2011a) "Changing ethical frameworks: From individual rights to the common good?". Cambridge Quarterly of Healthcare Ethics 20, 4, 533-545.

Sutrop, M. (2011b) "How to avoid a dichotomy between autonomy and beneficence? From liberalism to communitarianism and beyond". Journal of Internal Medicine 269, 4, 375-379. 
APPENDIX

\section{RECOMMENDATIONS ON CLINICAL ETHICS FOR ESTONIAN HOSPITALS FOR DISTRIBUTION OF LIMITED HEALTHCARE RESOURCES DURING THE COVID-19 PANDEMIC ${ }^{1}$}

As in the world at large, the spread of the COVID-19 pandemic to Estonia can bring about a situation in the near future where it is impossible to provide necessary medical treatment to all patients. Because of morbidity and quarantine, the normal work of physicians, nurses and other hospital staff and the availability of personal protection equipment, pharmaceuticals and medical supplies can be essentially disrupted. Although both the government and hospitals make great efforts to increase the above-mentioned resources and to hinder the spread of COVID-19 through restrictions on people's movement, the shortage of hospital beds, intensive care beds, ventilators, personal protection equipment and staff can cause a situation where more people need hospital treatment (including intensive care) than hospitals can offer.

To prepare healthcare providers and hospitals for taking difficult decisions, and in order to ensure that the patients, their families and the whole society understand them, it is necessary to formulate principles of ethical distribution of limited

\footnotetext{
1 The document was drawn up in cooperation between the Ethics Council of the North Estonia Medical Centre, the Ethics Committee of Tartu University Hospital and the Centre for Ethics at the University of Tartu with the participation of other experts in medicine, ethics and law. The responsibility for analysis of clinical medicine lies with Jaan Tepp and Kristo Erikson (North Estonia Medical Centre), for ethical analysis with Margit Sutrop (Centre for Ethics, University of Tartu and Collegium for Advanced Studies, University of Helsinki) and Kadri Simm (Centre for Ethics, University of Tartu) and for legal analysis with Jaan Ginter (School of Law, University of Tartu). General coordinator was Andra Migur (North Estonia Medical Centre). The document was drafted by Valmar Ammer, Katrin Elmet, Kristo Erikson, Jaan Ginter, Marten Juurik, Merit Kudeviita, Tiia Kõnnussaar, Elena Mahhova, Andra Migur, Mari-Liisa Parder, Meego Remmel, Kadri Simm, Margit Sutrop and Jaan Tepp. The consultants were Ants Nõmper, Veronika Reinhard, Andres Soosaar, Kadri Tamme, Peep Talving, and Joel Starkopf.
} 
resources. Several European countries (e.g. Austria ${ }^{2}$, Belgium $^{3}$, Italy ${ }^{4}$, Germany ${ }^{5}$, the $\mathrm{UK}^{6}$, Switzerland ${ }^{7}$ ) have already articulated distribution principles regarding resources of emergency medical services and intensive care during the COVID-19 pandemic. The North Estonia Medical Centre and the University of Tartu Hospital, which have borne the main responsibility for COVID-19 crisis management and supervision of medical staff in the northern and southern regions of Estonia, have requested the formulation of principles of action for taking ethically substantiated decisions, considering the number and status of patients, the staffing of hospitals and their provision with medical supplies, equipment and pharmaceuticals.

\section{Principles of action}

\section{Equal treatment of patients}

1. If the number of patients needing hospital treatment grows explosively and resources are extremely scarce, as many healthcare resources as possible will be primarily directed to preventing major damage. This will ensure the greatest benefit to the greatest number of people in society as a whole.

2. The medical system shall treat all patients equally regardless of whether they have COVID-19 infection or some other acute illness.

3. Earlier arrival for treatment does not give any patient an advantage compared to those who come later.

2 Allokation intensivmedizinischer Ressourcen aus Anlass der Covid-19-Pandemie (2020) Available online at $<$ https://www.oegari.at/web_files/cms_daten/covid-19_ressourcenallokation_garistatement_v1.7_final_2020-03-7.pdf $>$. Accessed on 6 April 2020.

3 Meyfroidt, G., E. Vlieghe, P. Biston, K. De Decker, X., Wittebole, P. Depuydt, ..., and D. Ledoux (2020) Ethical principles concerning proportionality of critical care during the 2020 COVID-19 pandemic in Belgium: advice by the Belgian Society of Intensive care medicine. Available online at $\quad<$ https://www.hartcentrumhasselt.be/professioneel/nieuws-professioneel/ethical-principlesconcerning-proportionality-of-critical-care-during-the-covid-19-pandemic-advice-by-the-belgiansociety-of-ic-medicine>. Accessed on 6 April 2020.

4 Vergano, M., G. Bertolini, A. Giannini, G. Mistraletti, and F. Petrini (2020) Clinical ethics recommendations for the allocation of intensive care treatments in exceptional, resource-limited circumstances. Available online at <http://www.siaarti.it/SiteAssets/News/COVID19\%20 -\%20documenti\%20SIAARTI/SIAARTI\%20-\%20Covid-19\%20-\%20Clinical\%20Ethics\%20

Reccomendations.pdf $>$. Accessed on 6 April 2020.

5 Entscheidungen über die Zuteilung von Ressourcen in der Notfall- und der Intensivmedizin im Kontext der COVID-19-Pandemie (2020) Available online at $<$ https://www.divi.de/empfehlungen/ publikationen/covid-19/1540-covid-19-ethik-empfehlung-v2/file>. Accessed on 6 April 2020.

6 COVID-19: ethical issues (2020) Available online at <https://www.bma.org.uk/advice-and-support/ covid-19/ethics/covid-19-ethical-issues>. Accessed on 6 April 2020.

7 Swiss Academy of Medical Sciences (2020) COVID-19 pandemic: triage for intensive-care treatment under resource scarcity. Available online at $<$ https://doi.org/10.4414/>. Accessed on 6 April 2020. 


\section{Decisions concerning intensive care during extreme shortage of resources}

4. During distribution of intensive care resources and in treatment decisions, prognosis for successful treatment outcome and future quality of life are primarily taken into account, in view of the patient's actual clinical status, concomitant diseases, general health status, other indicators relevant to the prognosis, and the patient's will.

5. Intensive care decisions are dynamic and can be re-evaluated across time (see assessment criteria, clause 4) with respect to the number and status of patients, hospital staffing and provision of the treatment facility with medical supplies, equipment and pharmaceuticals.

6. Conclusion. If the COVID-19 pandemic broadens, and there are not enough resources for all patients, the beginning and continuation of intensive care shall be re-evaluated (see assessment criteria, clause 4) with the arrival of each new patient (see clause 5), ensuring the equal treatment of both new and earlier patients; patients with COVID-19 and patients with other illnesses (see clauses 2 and 3 ).

All decisions are taken collectively by medical staff; they are substantiated, documented and communicated to patients' families.

7. If active treatment is interrupted, everything possible is done to relieve patients' sufferings and to ensure their humane and caring treatment.

\section{Patients and their families}

8. Health care providers do everything possible to identify the patient's will (their current, previous or presumable will) and to act in accordance with it, as well as to negotiate the treatment plan with the patient (or their family, should the patient lack the capacity for consent). If possible, patients should be asked about their will and preferences in advance, and the staff should negotiate with them regarding what to do if the situation becomes critical.

9. Informing the patient's family is particularly necessary if a decision is taken to interrupt active treatment and a plan of palliative treatment is drawn up, or if procedures regarding the end of life are performed. The staff of medical institutions understand that this means communicating difficult decisions and bad news, and that their manner of communication must be understanding, supportive and empathic.

10. Medical institutions make efforts so that patients do not feel abandoned during the ban on visiting because of the threat of infection and to ensure that patients keep contact with their families (e.g. by using various means of information technology).

To ensure patients' mental wellbeing, psychologists, pastoral counsellors and/ or clergy should be engaged. 


\section{Healthcare workers' protection and cooperation}

11. To ensure patients' treatment, heightened attention is paid to the protection of healthcare providers, as the success of fighting the pandemic depends on the maintenance of their health. The loss of each healthcare provider capable of work means a loss to the treatment of all patients.

12. Healthcare providers and hospitals all over Estonia support one another in such a difficult situation and cooperate benevolently by sharing their knowledge, experience, practices and resources.

\section{Ethical substantiation of principles of action}

\section{Principles of medical ethics}

The four significant principles of medical ethics - autonomy, beneficence, nonmaleficence and justice ${ }^{8}$ - remain relevant during the shortage of resources caused by the COVID-19 pandemic.

In a normal situation, clinical medicine is patient-centred: the duty of medical staff is to care for each patient's wellbeing and health (the principle of beneficence), avoid causing harm (the principle of nonmaleficence), consider patients' individual preferences and values (honouring their autonomy and human dignity), treat all patients equally and avoid discriminating anyone based on age, gender, mental or physical disability (the principle of justice). Relying on the principles of beneficence, nonmaleficence and justice, a physician must take equal care of all patients' life and health and avoid causing harm. Medical resources are limited even in a normal situation, and thus any kind of treatment must be justified, since a waste of resources on useless treatment unfairly reduces the availability of necessary treatment to other patients?.

In a disaster situation, following the principle of nonmaleficence becomes particularly important. The principle of autonomy states that the physician must always honour the patients' will. Patients capable of decision-making can express their will directly. Information about the patients' will incapable of decision-making can be obtained from their families or from their earlier written statements.

8 Beauchamp, T. L. and J. F. Childress (2019) Principles of biomedical ethics. 8th ed. Oxford University Press.

9 In practice, even in the normal situation most intensive care patients in Europe die after the decision not to start useless intensive care or to end applying intensive care procedures. Sprung C.L., B. Ricou, C.S. Hartog et al. (2019) "Changes in end-of-life practices in European intensive care units from 1999 to 2016". JAMA - Journal of American Medical Association 2, 1-13. doi: 10.1001/ jama.2019.14608 


\section{Ethical principles of disaster medicine}

In a pandemic situation, triage rules formulated for disaster medicine and emergency medical services may be helpful. A disaster is defined as a situation in which ordinary life is severely disturbed, in which the level of sufferings exceeds the community's coping abilities ${ }^{10}$. COVID-19 is an extensive global pandemic in which, as distinct from natural disasters, help cannot usually be expected from other countries, either because resources are scarce everywhere, or because states have closed their borders due to the threat of infection.

An essential principle of disaster medicine is that if limited resources make it impossible to ensure lifesaving treatment for all patients, it is necessary to act in such a way that major damage is avoided; this also helps ensure the greatest benefit for the greatest number of people in society as a whole. In a crisis situation in which resources are scarce and it is impossible to give necessary help to all patients, focus shifts from honouring individual values (autonomy, privacy) of ordinary medicine to supporting collective values (solidarity, reciprocity, safety); from individual benefits to community benefits.

\section{Individual benefits and benefits to the community}

The patient-centred approach of clinical medicine is replaced by a communitycentred approach oriented toward public health, in which the central place belongs to avoidance of damage, the principle of the greatest benefit and honest and transparent distribution of limited resources. This does not mean that beneficence, patients' autonomy (including informed consent) and the principle of human dignity cease to be essential - these continue to be in effect. When the principles of medical ethics are interpreted in the ethical framework of disaster medicine, fair distribution of existing resources (i.e. honest and transparent action, avoidance of discrimination), saving as many lives as possible (ensuring that the damage avoided is always greater than that caused by action) and ensuring the protection of healthcare providers become increasingly crucial concerns ${ }^{11}$.

In such situations, healthcare providers often face moral dilemmas in which they must choose between bad and even worse solutions. This situation is tragic in its essence, as no matter what decision is taken, each decision is accompanied by regret over the impossibility of doing everything that should have been done. Nonetheless, and regret notwithstanding, such a decision may be right, meaning that every other decision may even have been worse. Doing nothing also constitutes a decision and this can cause more harm than doing something. Inevitably, such a moral predicament puts great psychic pressure on health care providers and causes stress. This is precisely why it is essential to give healthcare providers a moral compass to

\footnotetext{
${ }^{10}$ United Nations (2009) 2009 UNISDR terminology on disaster risk reduction. Available online at $<$ https://www.unisdr.org/files/7817_UNISDRTerminologyEnglish.pdf $>$. Accessed on 6 April 2020.

${ }^{11}$ Swiss Academy of Medical Sciences (2020) 2.
} 
help them take the best possible decisions in any given situation. ${ }^{12}$

From a legal perspective, healthcare workers face a conflict among several obligations. In a given situation, the decision-maker has to fulfil that obligation which prevents the greatest extent of damage. An act that violates a legal obligation is not considered unlawful if a person is expected to perform several legal obligations simultaneously. It is impossible to perform them all, but the person must do everything in his or her power to perform an obligation which is at least as important as the one violated $^{13}$. The Penal Code of Estonia envisages a punishment for knowing refusal to provide assistance to a person who is in a life-threatening situation, but the conflict of obligations gives a physician the right to abandon intensive care treatment of a patient with a more negative prognosis if the same resources are needed for the treatment of another patient with a better prognosis.

\section{Recommended criteria for prioritising patients in a disaster situation}

In view of the above, the main criteria for prioritising patients in conditions of limited resources are their prognosis for treatment success and their predicted future quality of life. These criteria should be considered as carefully as possible, in the perspective of the patient's actual clinical status, concomitant diseases, general health status, other indicators relevant to the prognosis, and the patient's own intention. ${ }^{14}$

In a disaster situation, priority is given to patients whose probability of survival and prognosis of recovery (after intensive care) are greater. The argument of efficiency of medical services may also play a role - rendering help to patients for which its assistance has a more rapid, stronger effect, thus saving medical resources for the patients who follow. ${ }^{15}$

The principle of equal treatment ${ }^{16}$ requires that not only COVID-19 patients, but all patients needing treatment should be taken into account when distributing resources in a state of emergency.

${ }^{12}$ World Health Organisation (2016) Guidance for managing ethical issues in infectious disease outbreaks. Available online at $<$ https://apps.who.int/iris/handle/10665/250580>. Accessed on 6 April 2020.

${ }^{13}$ Estonian Penal Code, § 30: Conflict of obligations. Available online at $<\mathrm{https}$ ://www.riigiteataja. ee/en/eli/ee/522012015002/consolide/current>. Accessed on 6 April 2020. "An act which violates a legal obligation is not unlawful if the person is to perform several legal obligations simultaneously and it is impossible to perform all of them but the person does everything in his or her power to perform the obligation which is at least as important as the obligation violated against."

${ }^{14}$ See the recommendations of seven German speciality organisations about prioritising of patients: Entscheidungen über die Zuteilung von Ressourcen in der Notfall- und der Intensivmedizin im Kontext der COVID-19-Pandemie (2020) p. 6. Scheme in the same document pp. 12-13). The Estonian Anaesthesiologists' Society is currently actively engaged in creating support for decisionmaking.

${ }^{15}$ Swiss Academy of Medical Sciences (2020) 3.

${ }^{16}$ Constitution of the Republic of Estonia, $\S 12$. Available online at $<\mathrm{https}: / / w w w . p r e s i d e n t . e e / \mathrm{en} /$ republic-of-estonia/the-constitution/index.html>. Accessed on 6 April 2020. 
During the COVID-19 pandemic, the main criteria for the beginning or continuation of intensive care should be the medical outlook regarding treatment success and a favourable prognosis for future quality of life. Although concomitant and chronic diseases are known to be the main factor influencing treatment success, and more advanced age is with greater statistical frequency associated with concomitant and chronic diseases, patients - as in any ordinary situation - should not be discriminated against based on their age during the COVID-19 pandemic.

In taking treatment decisions, a person's gender, ethnicity or social status must not play a role. The ban on discrimination contingent on the framework of human rights does not lose its validity in a state of emergency. During a crisis, special attention must be paid to communication with patients and their families. ${ }^{17}$

If possible, hospitals should consider engaging additional resources (e.g. psychologists, pastoral counsellors, clergy, and other helpers).

${ }^{17}$ See e.g. VITALtalk (2020) COVID ready communication playbook. Available online at $<$ https:// www.vitaltalk.org/guides/covid-19-communication-skills/>. Accessed on 6 April 2020. 